University of South Florida

DIGITAL COMMONS

Digital Commons @ University of

@ UNIVERSITY OF SOUTH FLORIDA

South Florida

\title{
Graduate Education and the Evolving genre of Electronic Theses and Dissertations
}

Joseph M. Moxley

University of South Florida Department of English, moxley@usf.edu

Follow this and additional works at: https://digitalcommons.usf.edu/eng_facpub

\section{Scholar Commons Citation}

Moxley, Joseph M., "Graduate Education and the Evolving genre of Electronic Theses and Dissertations" (2002). English Faculty Publications. 138.

https://digitalcommons.usf.edu/eng_facpub/138

This Article is brought to you for free and open access by the English at Digital Commons @ University of South Florida. It has been accepted for inclusion in English Faculty Publications by an authorized administrator of Digital Commons@ University of South Florida. For more information, please contact digitalcommons@usf.edu. 


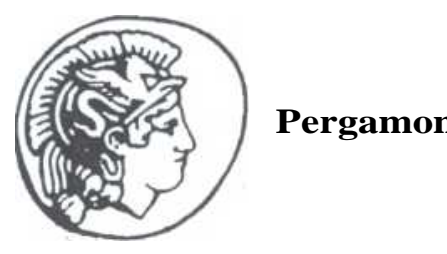

Computers and Composition 19 (2002) 89-104

\title{
Computers and Composition
}

\section{Graduate Education and the Evolving genre of Electronic Theses and Dissertations}

\author{
Jude Edminster*, Joe Moxley \\ University of South Florida, Tampa, FL 33620, USA
}

\begin{abstract}
Electronic writing spaces are transforming graduate education-enhancing mentoring and the shape of dissertation content. In this article, we review international efforts to develop the Networked Digital Library of Theses and Dissertations (NDLTD). We examine the need to amplify access to current scholarship, the need for training materials and centralized metadata, and the need to develop multi-language search interfaces. We explore ways traditional print dissertations are being remediated by electronic writing. We analyze challenges to implementing ETD initiatives, including concerns about preservation, attitudes toward intellectual property, and the training challenges involved in deploying technology to present new research using media and interactive perspectives. We conclude that universities need to develop and support ETD initiatives to provide broader access to their research and to provide students with the training and tools they need to present their knowledge more effectively in a digital world. (C) 2002 Elsevier Science Inc. All rights reserved.
\end{abstract}

Keywords: Digital libraries; Dissertation; Electronic writing; Graduate education; Multimedia; New media scholarship; Thesis

\section{Introduction}

Universities in the United States have been slower than their international counterparts to embrace electronic theses and dissertation initiatives. India, Australia, Canada, France, England, Germany, the Organization of American States, and the United Nations-all are committed to the increased sharing of global knowledge through digital libraries of Electronic Theses and Dissertations (ETDs). India, Australia, Germany, France, and Canada are in the process of implementing policies at the national level to guide and standardize the development of local ETD initiatives. And while UMI (a division of Bell and Howell) has successfully

Email address: jedmins」@tampabavrr.com (J. Edminster). 
l aunched a corporate enterprise making all of its dissertations available online, U.S. universities continue to struggle with the decision to facilitate electronic access to graduate student research. Still, as we explored these issues, we found that the Networked Digital Library of Theses and Dissertations (NDLTD) is leading exciting initiatives to truly transform graduate education in the United States, as well as in the international academic community.

The term ETD refers to a master's thesis or doctoral dissertation that is archived and circulated electronically rather than archived and circulated in print. Most ETDs take the form of text uploaded in a word processing format or in an Adobe portable document format (PDF) and look much like traditional print dissertations. These documents can be viewed with the free ADOBE ACROBAT READER and are searchable with licensed Adobe Acrobat software (a different version than the Reader). Increasingly, though, ETDs are uploaded in more sophisticated formats such as HTML and XML and include color images, streaming multimedia, animation, and interactive features. They may reside on a CD-ROM or the World Wide Web, where they are highly accessible to broad audiences.

Electronic thesis and dissertation initiatives are an important issue for the computers and composition writing community for two reasons. First, the digital divide is not only a technologi cal divide but an informational divide as well; in fact, the two can hardly be separated. Those of us concerned about making information more widely accessible to those on the impoverished side of the gap will find that ETDs and the global initiatives they generate can bridge this dual divide. And second, the traditional print dissertation is a genre that has remained relatively unaffected by structuralist and poststructuralist critiques of authorship; indeed, one of its frequently stated primary purposes is for a solitary "author" to make an "original" contribution to scholarship. The perpetual reinscription of this Romantic notion of authorship in almost every dissertation written by graduate students throughout academe has considerable consequences for the shaping of our written knowledge. As we show in this article, ETDs provide powerful alternatives to the authorial traditions associated with the presentation of research.

We provide an overview of the international efforts to develop a world-wide digital library of theses and dissertations by focusing on (a) the need to provide developing countries with equal access to current international scholarship; (b) the collaborative development of training materials to facilitate wider global participation in the NDLTD; (c) the work of multi-university/library and corporate collaborations to establish centralized metadata for ETDs; and (d) the development of multi-language search interfaces. We report on the initiatives of early adopters in the United States, and discuss the results of a survey of best practices. Our overview also explores the origins of the traditional print dissertation and ways the genre is being reconfigured by the possibilities electronic writing offers. Challenges to widespread adoption of ETDs in the United States, including concerns about preservation, cultural attitudes toward intellectual property, and the need for partnerships with educational institutions at the national level are also analyzed. Finally, we examine the training challenges involved in deploying technology to present new research using multimedia and interactive perspectives.

\section{Overview of the international initiative}

ETD initiatives have come a long way since 1987 when the first meeting to discuss the concept of a worldwide digital library of graduate student research took place. The gathering 
was arranged and hosted by UMI at their corporate offices in Ann Arbor, Michigan, and was attended by representatives from Virginia Polytechnic Institute and State University (Virginia Tech) and the University of Michigan. Since that time, Virginia Tech has led the way in securing and providing the funding, research, and development necessary for generating successful document type definitions for publishing ETDs on the Web, as well as exploring the challenges associated with producing, archiving, and accessing these works. In addition to the over-arching goal of amplified access to cutting edge research, the original Virginia Tech initiative continues to emphasize improved graduate education through requiring students to publish their work as ETDs, providing the training necessary to produce these highly visible documents, and preparing graduate students to conduct and publish research in a medium which is clearly gaining ascendancy in an information-based economy. The potential for ETD accessibility is demonstrated by Virginia Tech's download statistics, which can be viewed at $\langle\mathrm{http} / / \mathrm{sch}$ olar lib vtedu/theses/data >. In the 3 years following submission of the first ETD, requests to view ETD abstracts were exceeded dramatically by requests to view the full text document. In 1996, there were 25.829 requests for ETD abstracts and 4,600 requests for ETDs themselves; by 1999 (January-August), there were over 143,056 requests for abstracts and 244,987 requests for full text ETDs. As of October 1999, the most popular ETD at Virginia Tech had been requested over 75,000 times.

This increased access to graduate level research has garnered the attention of the Organization of American States (OAS) and the United Nations Educational, Scientific, and Cultural Organization (UNESCO). The benefits to the global community of having free and amplified access to current research, particularly in developing countries, were quickly perceived by these organizations, both of which are current members of the NDLTD. The use of information technology is one of OAS's primary goals in promoting

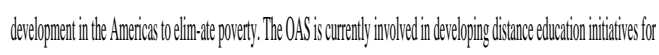
this purpose, and digital libraries Such as the NDLTD have much to offer them in their efforts INDLTD Steering Committee Meeting, September 15. 2000). According to Mohsen Tawfik of UNESCO, of its 187 member states, at least two-thirds remain uninformed about both the amplified access to current scholarship provided by ETDs and the benefits of involvement in ETD initiatives. Therefore, three organizational missions are critical for them at this point: raising awareness among member states, creating a positive attitude, and beginning a plan of action in each country or region at the national or regional level. Noting that outside the United States. perhaps more than $90 \%$ of the universities are government entities rather than private institutions, Tawfik indicated that the role of national libraries will be key to ETD initiatives among the developing countries (NDLTD Steering Committee Meeting, September 15, 2000).

As part of its commitment to training issues, UNESCO is funding the collaborative authorship of an International Guide for the Creation of Electronic Theses and Dissertations. It will introduce ETDs as a new genre of documents and present the benefits to both graduate students and universities. Written by ETD leaders worldwide, this guide will reveal diverse best practices, highlighting different universities' approaches to growing ETD practices. Technical issues related to the production and dissemination of ETDs, such as required hardware and software mark-up languages. style sheets, metadata models for searching, backups and interfaces $w$ ill be covered in detail. An extensive section on training w ill provide toolkits for trainers, demonstrations, and valuable information on standards arid successful development of 
broad local teams. Plans are to leverage the International Guide for the Creation ofElectronic Theses and Dissertations into an international training initiative that will continue to be funded by UNESCO (NDLTD Steering Committee Meeting, September 15, 2000).

Face-to-face annual conferences are frequently the only occasions for many international scholars to present their dissertation research to audiences outside their own countries. Making this research more accessible is also a primary goal of the NDLTD. According to steering committee member Marian Bates from the University of New South Wales, Australian universities are eager to achieve better distribution for their dissertations outside the country. Australia has 39 institutions in its university system, 7 of which originated ETD initiatives at their own campuses and subsequently mentored the development of digital theses at 6 more institutions. Rcgional support structures currently under development should allow for quicker adoption of ETDs. Australia's NDLTD member institutions are working closely with the National Library of Australia on preservation issues. The Australian Digital Theses Program was initially funded by the Australian Research Council and has as its unique feature a collaborative approach in developing a sustainable method for distributed input to form a central metadata database of digitized theses-a national database (NDLTD Steering Committee Meeting, September 15, 2000).

Establishing internationally user-friendly, centralized metadata for ETDs is the goal of the current collaboration between the NDLTD and Virginia Tech Library Services Inc. (VTLS), a corporation that develops, markets, and supports solutions for managing library collections and for accessing information via computer networks. VTLS has agreed to provide the NDLTD with free technology that allows ETD metadata to be entered into a single database in any language. including non- Romance languages such as Arabic, Chinese, English, Greek, Hebrew, and Russian. In addition, VTLS will actively promote the NDLTD among its diverse customer base of more than 900 libraries, located in 32 countries (NDLTD Steering Committee Meeting, September 15. 2000).

Working with multi-language and multi-script requirements and developing multi-language search interfaces is another challenge facing the NDLTD. Professor Shalini Urs of Mysore University, India, is presently working with her collaborator, Professor K. S. Raghavan, to overcome problems associated with these issues. Because she comes from a developing country that speaks hundreds of languages and dialects in addition to English, Dr. Urs is uniquely qualified to contribute to the UNESCO Guide in this area. Plans are underway to establish a National Centre for ETDs at Mysore, where formal guidelines for language issues will eventually be developed. Dr. Urs is also the Director of VIDYANIDHI, an organization whose name means "wealth of learning." Their Information Technology (IT) action plan calls for mandatory ETDs for all of India's member universities. Technology training and workshops for ETDs are funded by the Indian government's Department of Science and Technology, and many organizations that fund doctoral research in India have targeted funds for ETDs (NDLTD Steering Committee Meeting, September 15, 2000).

\section{UMI role}

As a member organization of the NDLTD, UMI has been an influential player in institutionalizing ETDs. UMI has been the established central repository and disseminator 
for print dissertations in the United States over the last 50 years. Currently. UMI scans all the print dissertations it receives and converts them to PDF files which are now available to be downloaded via the Internet for the same fee required for a print copy. It also accepts dissertations submitted in electronic format without a print copy. ETDs at UMI are stored on three or four servers with a 3-year refreshing cycle. According to Delphine Lewis of UMI Dissertations and Books on Demand, UMI is "looking for a lot of ways to use ETDs" (NDLTD Steering Committee Meeting, Washington D.C., September 15, 2000) (See $\langle$ http://dmi.usf.edu/edminster/ETDProposal/DelphineLewisInterview.wav > for sound file of this interview). Including them as part of course packs in which they may be viewed at no charge (downloadings would be charged) is one idea currently under consideration. In order to accommodate the needs and budgets of developing countries, UNIT is looking into the possibility of differential price structures for accessing ETDs. Work is currently underway in this area with African universities (NDLTD Steering Committee Meeting, September 15, 2000). Another innovative use of ETDs by UMI is their Current Research@ service available at <http://wwwlib.umi.com/cresearch/gateway/main >. Users can search citations and abstracts of dissertations and theses submitted by participating institutions and view 24-page previews of dissertations published after 1996; in addition, authorized users from participating institutions can download the full text of dissertations and theses published after 1996 at no cost. Over 190 institutions participate at this UMI site including Harvard, Brown, Carnegie-Melton, University of Chicago, and several of the Big Ten state universities <http://wwwlib.umi.com/cresearch/main >. However, unlike many member universities of the NDLTD whose full text works are accessible free of charge to all users, UMI is currently limited in its handling of multimedia dissertations. Almost all those available for preview and downloading through Current Research@ are preserved as PDF files. But a number of those housed at the NDLTD contain images, sound files, animation, video, and other interactive features. According to Lewis, UMI needs to be ready as the genre of the electronic dissertation evolves. Currently, every dissertation sent to UMI is stored in TIE, PDF, and microfilm; and increasingly "we are looking to XML" (Lewis, personal communication, March 25, 2001).

\section{United States innovators and early adopters}

Although U.S. participation in the NDLTD has been tentative so far, six universities do currently require students to publish their dissertations electronically, and two plan to do so in the year 2002. Virginia Tech instituted the requirement in 1997. West Virginia University, East Tennessee State University, and the University of North Texas followed within 3 years. The University of Texas at Austin joined this short list of innovators in May 2001, and the University of Florida followed in the fall of 2001. Virginia Tech has developed a multi-faceted Web site for the NDLTD that chronicles the history of the digital library's development, assists students in creating and submitting ETDs, provides links to member university ETD libraries and initiatives, as well as links to and citations for recent conference presentations and publications about ETDs <http://www.ndltd.org >. This site is an invaluable resource for institutions just beginning to explore the potential of digital documents. At East Tennessee State University, communications with faculty, students, and policy making bodies has been the most 
important and effective measure taken to facilitate the success of ETDs and the achievement of a mandatory requirement, followed closely by linkage with the library and careful staffing of the early initiative (Wesley Brown, personal communication, October 3, 2000).

In August of 1996, the Graduate Council at North Texas University concluded that "Given the increasing use and sophistication of technology and the increased movement toward distance learning education, electronic transmission of theses and dissertations is inevitable" (Electronic Transmission of Theses and Dissertations at UNT A Report from the Ad Hoc Committee, 1997, p. 1). Following a careful study of the advantages, challenges, costs, appropriate ETD format, technology requirements, library involvement, and impact on (a) the roles and responsibilities of graduate committees, and (b) graduate school and university policies, the Council recommended that UNT "develop policies and procedures permitting, encouraging, and ultimately requiring electronic filing and archiving" (p. 3). PDF was chosen as the standard format, with the acknowledgment that other file formats permitting the use of hypertext, video, and other complex media might be feasible in the future.

The University of Texas at Austin (UT) was first prompted to consider submission of dissertations in forms other than the traditional print medium when a doctoral student in speech communication asked the Graduate School to permit her to submit a CD-ROM dissertation without a print copy. After a thorough study of the advantages and challenges associated with ETD production, UT instituted a limited program operating with a small number of students whose participation would be studied to determine the kinds of support they would need to create dissertations in digital formats. From the beginning, tools training for students was viewed as vital to the project. Mandatory attendance at workshops on intellectual property issues was also recommended (UT Office of Graduate Studies Electronic Dissertations, 2001). Currently, an informative collection of pages on electronic dissertations exists as part of the UT Web site where students can find answers to questions about ADOBE ACROBAT (the software required to produce PDF files), how to create links in PDF files, and acceptable file formats for images, video, audio, and text <http///wwwlibutexas.edu/etd >.

\section{Survey of best ETD practices}

As part of an ongoing research project at the University of South Florida, Jude Edminster is conducting an online survey of NDLTD member institutions. Edminster is examining how various ETD initiatives are being developed. Of 101 members asked to participate, 28 have responded so far to questions about faculty and student education and training, funding and administration, digital library content, accessibility and preservation, and submission guidelines and requirements. According to current data, workshops and Web documents are most often used to educate students about ETDs, although faculty and administration learn about them mainly through presentations and university publications. According to the survey, $66 \%$ report that in general, faculty are supportive of ETDs at their institutions. Two-thirds of the technology training students receive is associated with using PDF in the submission process, but $54 \%$ also provide training in MICROSOFT WORD, and $41 \%$ train students to use Web authoring tools. This training typically takes place in workshops or on the Web; however, only $8 \%$ of those responding indicated that such training was available to all graduate students in the 
form of courses for credit. Few substantial incentives are offered to students to produce ETDs where they are not required, with only $6 \%$ offering any funding for individual student projects. Funding for the entire initiative most often is provided by the institutions themselves and falls in the range of $\$ 0-\$ 50,000$; much of the work associated with member initiatives proceeds through the volunteer efforts of faculty, students, and staff. The majority are coordinated by university library staff and graduate deans, together with strong IT involvement. Over $80 \%$ of the members permit students to submit multimedia work, and nearly half report that their digital libraries contain multimedia theses and dissertations; however, $95 \%$ are the traditional print variety preserved in PDF. Those which do contain multimedia are preserved in a variety of formats, including HTML, JPEG, POWERPOINT, POSTSCRIPT, AND ARCVIEW. Students use a variety of tools to write their ETDs; MICROSOFT WORD, MICROSOFT EXCEL, ADOBE ACROBAT, and ADOBE PHOTOSHOP are the most popular; $27 \%$ are constructed with various Web editors. Encouragingly, over $20 \%$ of those surveyed reported that their institutions allow annotation of ETDs, facilitating the development of dynamic, continuously interactive research documents. Twenty-eight percent expect ETDs to be required at their universities within 10 years (NDLTD Member Survey, 2001).

\section{Graduate education and the evolving genre of the dissertation}

Graduate education in the United States was initially patterned after the organization of teaching and research carried out at German universities. During the nineteenth century, a dual migration of U.S. students traveling to Germany to further their studies and German teachers immigrating to the U.S. to teach college facilitated "the influence of German university methods, forces and conditions, over the teaching given and over the methods and conditions prevailing in American institutions" (Thwing, 1928, pp. 10-11). Approximately 10,000 U.S. students made their way to German universities from 1815 to 1900 to obtain graduate degrees, including the $\mathrm{PhD}$, from institutions which enjoyed considerable prestige in Europe for both their contribution to the advancement of scientific knowledge and their superior libraries. In addition, German university laboratories, as well as their investigation and research methods, had strong appeal (Malone, 1981). The work performed in these laboratories for which students sought scholarly recognition and status "was associated more and more widely with research and writing (and usually publication as well) of a doctoral dissertation disputation, the traditional standard exercise for achievement of the dignity of doctor, died out in this period" (McClelland. 1980, p. 198).

In the German laboratories, the public expression of knowledge required for the granting of doctoral degrees in the medieval university began its transformation from a series of oral arguments, which were necessarily dialogic and polyvocal in nature, to the univocal, linear text-a text representing the independent inquiry and authorship of a single individual. Its purpose in graduate education remains the same today across the disciplines, despite serious critiques of both the Romantic notion of authorship and the epistemological assumptions that inform traditional notions of independent scientific and scholarly inquiry. The most popular, six-chapter structure for the dissertation in use today, consists of (a) introduction, (b) review of the literature, (c) methodology, (d) results/findings, (e) analysis and interpretation of findings, 
and (f) summary, conclusions, applications, and recommendations for further study (Thomas \& Brubaker, 2000). This structure continues to follow closely an empirical model of researcha model in which the "reality" under investigation speaks for itself and assumes the role of univocal authorship. The text is merely a transparent window through which a stable reality may be viewed.

Although some modification of the six-chapter format occurs in dissertations in the humanities, its influence is still clearly visible in most graduate work. And the view that such work represents original thought by an individual author who merits recognition and reward for that originality continues to prevail.

Across the disciplines, the traditional print dissertation fails to acknowledge or address what Gunther Kress (1999) sees a dramatic transformation of representational alternatives and resources that is taking place in the construction of knowledge. This is true even though, knowledge in many disciplines is being constructed in a far more self-reflexive, less "objective" fashion; in the social sciences, Kate Lenzo (1995) has argued that pursuing the Faucaldian-based concept of validity as an "incitement to discourse" requires scholars to abandon the "traditional forms of closed narrative with tight argument structures [in favor] of more open forms with holes and questions and explorations of situatedness and partiality" (p. 19). We see electronic text as an alternative representational resource that can provide students with a way to refuse a singular subject position within their dissertations. Because it is often a series of linked texts-a decentered, less unified text-it can enable them to "understand [themselves] reflexively as persons writing from particular situations at specific times," and thus liberate them from having to "write a single text in which everything is said to everyone" (Richardson, 1994, p. 518). Moreover, including external links within the text foregrounds the polyvocal nature of scholarly work reifies writing as a network of texts (Bolter, 1991, p. 23) and effaces the univocal assumptions underlying traditional readings of scholarship. Electronic text allows readers far greater flexibility in navigating a text for specific information-essentially creating their own text-and thus, provides a means for graduate students to successfully reach more diverse, perhaps more interdisciplinary audiences. Color images, streaming video, animation, and sound files extend the representational limits imposed by the single mode of text so prevalent in dissertations, offering "an enormous potential enrichment, cognitively, conceptually, aesthetically and effectively" (Kress. 1997, p. 29). This transduction across modes encourages transformative, creative action on the part of both researcher and reader and also represents "an essential skill for the social and economic futures of the postindustrial western world" (p. 29). And because the composition of the dissertation serves in substantial ways (though certainly not exclusively) as a model for composing future scholarship (Parry, 1998), composing it in electronic media can prepare students to productively facilitate the inevitable remediation of print scholarship. Most theses and dissertations published in the NDLTD are PDF files uploaded to the Web that remain faithful to the conventions of traditional print. However, the digital medium has the power to be more aggressive in its remediation, refashioning the older medium entirely. Media theorist Steven Holtzman argues that once new media find their authentic aesthetic, their "unique qualities... will ultimately define entirely new languages of expression. And it's those languages that will tap the potential of digital media as new vehicles of expression" (Holtzman, 1997, p. 15). And as Mercy Bauman (1999) argues: 
In this time of unprecedented change, the genres we can invent and the genres weal low ourselves to use as a profession will determine the ways we can act in the world. We owe it to ourselves to draw the parameters as broadly as we can. (p. 281)

\section{Challenges to widespread diffusion and adoption of ETDs}

Given the potential national and international impact and importance of the benefits of electronically published current graduate student research, why is the concept of ETDs slow to diffuse, especially in the United States? What are some of the more salient concerns graduate schools and libraries have with moving toward exclusive electronic publication of theses and dissertations'?

Permanent and secure preservation of documents is often an issue; the tension between libraries' two-fold responsibility of preserving and providing access to information takes on particular significance with ETDs. Many universities balk at the idea of allowing students to submit work exclusively in electronic form, and they continue to require what is perceived to be a more "permanent" print copy for archival purposes, even when this places an additional burden on students whose dissertations are nonlinear and contain multimedia files. Moreover, such print versions of native hypertexts and other electronic representations of information often result in a document that may record the data, but fail to accurately reproduce the meaning (or possibilities for meaning) contained in the original. In lieu of print, some universities will accept an archival version on CD-ROM, but there are concerns as to the long-term durability of this technology as discs begin to deteriorate in 15 to 20 years. Archiving documents electronically also raises concerns about the logistics of their eventual and inevitable migration to new formats. The long-term preservation of digital scholarship al all levels is an ongoing concern that we do not intend to minimize unduly. However, the concept of permanence as it has traditionally been understood in the field of library science is beginning to show signs of undergoing transformation:

The digital age has led to a widening of the concept of permanence. There was a stage in which we worried mostly about the physical longevity of the information carrier itself because we are used to the idea that if the carrier of the information survives, then the information it carries will survive also. In fact, this has never been true. We are now sensible enough to realize that we need to be concerned about the permanence of the information itself. rather than its carrier.

(Exon. 1995, Definitions of Permanence and Durability section, para1)

Information's best chance of survival is high accessibility and continued use. Both data and meaning survive when new generations of scholars can access and incorporate the work of others into their own, continually reproducing and developing ideas the culture finds useful. Amplified access to an international network of ETDs can contribute much to the dissemination and preservation of knowledge by facilitating its current and expansive use.

Creating conditions that favor the production of useful ideas introduces one of the most complicated matters associated with ETDs-that of intellectual property protections for authors. We discuss this issue at length here because its resolution may be crucial to achieving high levels of accessibility, arguably the most important benefit of electronic publication of theses 
and dissertations. Moreover, the contribution of the Romantic construct of the "author-genius" to copyright law is substantial (Woodmansee \& Jaszi, 1995), and "we should beware of efforts to regulate the digital environment as if it were simply a new vehicle for individual 'works of authorship' rather than a potential cultural `commons' " (Woodmansee \& Jaszi, 1994, p. 13).

Questions about intellectual property are often tied to concerns about whether electronic publication of a thesis or dissertation constitutes prior publication with respect to future efforts to publish student research as a book or a journal article. Much confusion surrounds these discussions, and because Web technology and the publication opportunities it affords are so new, answers to questions that arise do not often appear simple or clear cut. Although the Digital Millennium Copyright Act of 1998, an amendment to existing U.S. Copyright law, addressed many of the newer issues concerning electronic publication, most intellectual property considerations raised by graduate students and advisors are of a more traditional nature. Romantic notions of authorship again come into play, as amplified access in and of itself appears to increase uncertainty about protecting the originality of scholarly contributions.

The difference between copyright violation and the threat of plagiarism is often confused in discussions about intellectual property. Plagiarism occurs when someone poses as the author of a work; copyright infringement occurs when someone uses another's work without proper authorization. There is a distinction between the two, and neither necessarily implies the occurrence of the other. Sources are cited to avoid the charge of plagiarism; permission of the author is obtained to avoid the charge of copyright infringement (Scheftic, 1997). The notion that amplified access to ETDs via the Web somehow increases the likelihood that both plagiarism and copyright infringement will occur is apparent in discussions about intellectual property issues. At Virginia Tech, one-third of students required to submit ETDs elected to restrict public access to their work. No archival copies of their dissertations are available, nor does UMI receive a copy. Restrictions are renewable on a year-to-year basis.

Graduate students have for some time now been permitted to retain the sole copyright for their print dissertations (except in some situations involving outside funding for research, in which case copyright may be held jointly with the funding institution and/or the university), and this does not change with electronic publication. Graduate students also have been able to restrict their university's or UMI's circulation of copies of their work in order to protect patent right applications in progress, to secure future publication in another form or to protect student interests for any other reason deemed necessary. Such dissertations essentially remain unpublished. Again, this does not change with ETDs. What does change, however, is the degree to which students can restrict access to their work. In the past, ordering a copy of a dissertation through interlibrary loan or from UMI meant ordering a full and complete copy of the document. With an ETD, however, students can elect to allow access to certain portions of their work while controlling or monitoring access to more sensitive material in the dissertation by securing those pages with passwords. They can also restrict access to local users, for example, students and faculty at their own universities.

In a professional paradigm where the publication of original work is the coin of the realm, students and faculty advisors are naturally concerned about providing open access to dissertations that may or may not count as prior publication or that contain information considered sensitive in fields where competition for original credit is high. However, in a recent survey of 
journal editors and publishers, $82 \%$ said that an online thesis or dissertation widely available through a Web-based archive would not be considered prior publication according to their journals' existing policies; only $4 \%$ said that an online thesis or dissertation with access limited to campus or institution would be considered prior publication (Electronic Theses and Dissertations: 2001 Survey of Editors and Publishers, 2001). Yet, 40\%n of graduate students who publish ETDs are advised by faculty to restrict access in order to protect their professional interests (2000/2001 Author Survey, 2001). Such restricted access threatens to undermine the very purpose for which the NDLTD was created. Although student rights to restrict access are quite legal, an emphasis on those rights can perturb the balance between private interest and public access that U.S. Copyright laws, together with World Intellectual Property Organization treaties, were originally designed to achieve.

Interestingly, the primary purpose of U.S. Copyright law as set forth in Article I, Section 8 of the Constitution is to "promote the Progress of Science and the useful Arts." Securing the rights of authors and inventors for a limited time is but the means devised to achieve this end. Author rights are intended as an "inducement to develop new work not to promote the author's own interests or increase the author's own wealth" (Scheftic, 1997, Intent of Copyright Protection section). As early as 1909. the U.S. Congress indicated that:

The enactment of copyright legislation by Congress under the terms of the Constitution is not based upon any natural right that the author has in his writings, for the Supreme Court has held that such rights as he has are purely statutory rights, but upon the ground that the welfare of the public will be served and progress of science and useful arts will be promoted by securing to authors for limited periods the exclusive rights to their writings. Not primarily for the benefit of the author, but primarily for the benefit of the public, such rights are given. Not that any particular class of citizens, however worthy, may benefit, but because the policy is believed to be for the benefit of the great body of people. (H.R Rep. No. 2222, p. 7)

And as recently as 1984, in Sony Corporation of America v. Universal City Studios Inc. (1984) the seminal copyright case that made home viewing of film industry productions on video tape possible, the Supreme Court wrote: "The monopoly privileges that Congress may authorize are neither unlimited nor primarily designed to provide a special private benefit. Rather, the limited grant is a means by which an important public purpose may be achieved" (p. 782). Copyright law strikes a critical balance between authors' rights to produce and protect their original work (with society as the intended benefactor of such author protection) and society's rights to both the free flow of information and the freedom to build on the ideas of others. However, as Martha Woodmansee and Peter Jaszi (1995) note in their College English publication, "The Law of Texts: Copyright in the Academy," more recently,

\footnotetext{
courts have taken their charge to safeguard "original authorship" ever more seriously, with the result that the intellectual commons on which we may draw freely as writers and readers, scholars and teachers, is shrinking fast. This enclosure of the public domain is making itself felt both locally and globally, and the chief engine of this trend is the Romantic authorship construct. (p. 772)
}

This construct, which emerged from literary and artistic culture and was subsequently mobilized in legal discourse, is still powerful and persistent in the structure of copyright doctrine 
today. Indeed, Jaszi (1991) names it as "the specific locus of a basic contradiction between public access to and private control over imaginative creations" (p. 457). Uncritical assumptions about the moral rights of authors-as "creators" in possession of undisputed authority over their works-fuel the legal sanction of what amounts to "a charter for private censorship" (p. 497).

If we are to realize the potential that ETDs have to further equitable distribution of the information wealth many cultures in the West take for granted, then perhaps graduate students' more studied consideration of the ethical limits of authorship rights is warranted. When professional futures depend on original contributions to scholarship made by solitary student authors, it is admittedly difficult to weigh the social benefits of amplified access to information against the private costs of neglecting its protection. However, if students and advisors continue to perceive electronic access to their work as a threat to future publication or employment, many will continue to lock out readers from their documents, precluding even fair use by those seeking to productively transform or build on the ideas of others. Currently, restrictive views of fair use provisions limit access by scholars to unpublished archival source materials (Woodmansee \& Jaszi, 1994). Although the fair use section of the Copyright Act states that "the fact that a work is unpublished shall not itself bar a finding of fair use," unpublished archival works are also protected by copyright law's extension to the author of the "right of first publication" (Copyright Act of 1976). This right seems to be at the heart of most concerns graduate students and faculty advisors have when deciding whether or not to publish a dissertation as an archived document that can be obtained via interlibrary loan, purchased through UMI, or simply viewed in a browser window at no charge through the NDLTD.

The Romantic aesthetic of the solitary author has worked to shape both Continental and U.S. Copyright law, and it continues to remain unaffected by literary criticism's pronouncements of the death of the solitary author or composition studies theories of social construction (Woodmansee \& Jaszi, 1995). And as we noted earlier, the dissertation itself continues to count as a text by a single author making an original contribution that becomes private property. Dissertations continue to he written and defended, doctoral degrees granted, and faculty positions awarded according to these terms of evaluation. And as Candace Spigelman notes: "Students who believe that their evaluation will be based on their text's originality may be quite protective of their texts and fearful of having their ideas stolen. Anxiety about originality may produce a competitive climate of hoarding and hiding" (Spigelman, 2000, p. 9). Whether or not limiting or precluding access to ETDs constitutes behavior that can be characterized as hoarding and hiding, interpretations privileging the private rights of authors over those of the public will produce an environment in which it is increasingly more difficult and expensive to undertake scholarly projects (Woodmansee \& Jaszi, 1995).

Our final thoughts in this section briefly address the need to foster the relationships many other countries in the NDLTD have with their governments and national libraries. For example, the National Library and the Canadian Initiative for Digital Libraries are currently working with upper-level university administrators towards formulating a national recommendation to i mplementation of ETD initiatives at all Canadian universities. Together they are working to centralize ETD metadata on a national level. Australia, too, continues to work closely with its National Library to develop regional support structures for ETD initiatives. Although the U.S. Library of Congress receives a digital copy of all PDF files of dissertations that exist at UMI, 
these documents can only be accessed from within their own network. Ironically, one must travel to the Library of Congress itself to view digital copies of dissertations archived there.

On a more positive note, the Online Computer Library Center (OCLC) is a national organization with extended, ongoing support and involvement with electronic dissertations and the NDLTD, facilitating access to many ETDs through their online database. They are represented on the NDLTD Steering Committee and have taken an active role. Beyond the university, at the state, regional, and national level, we need to work out appropriate partnerships, ensuring common authoring and archiving and metadata standards, and sharing best practices and training resources.

\section{Training issues}

U.S. universities need to recognize the potential value of accessible electronic theses and dissertations. Theses and dissertations reflect an institution's ability to lead students and support original work. In time, as digital libraries of ETDs become more commonplace, students and faculty will make judgments regarding the quality of a university by reviewing its digital library. Universities must respond accordingly, ensuring they provide the resources and training students need to incorporate new literacy tools, such as animation, graphics, sound, and streaming multimedia. Graduate students trained to use new communication technologies can be provided with an integrated set of faculty reviews, regardless of their location in time and space; when dissertations in progress are made available on the Web, students can invite other scholars to contribute to the development and presentation of their ideas and to share the information contained in literature reviews and bibliographies. At the Universite de Montreal, a pilot project to help train students in the efficient use of word processors to construct their ETDs is currently underway. Although most graduate students have been using the basic features of tools such as MICROSOFT WORD to produce print versions of their dissertations for several years now, Guyllaine Beaudry of the university's library services reports that many are still unfamiliar with the use of style sheets and other more sophisticated features that can significantly reduce the amount of time spent organizing text (NDLTD Steering Committee Meeting. 2000). Offering credit for courses designed specifically to address these needs early in graduate study would give students the incentive and opportunity to increase technical skills before they begin developing research projects.

Tools training must also involve instilling an awareness of new ways to make meaning when we creatively exploit tool capabilities. What we mean by the practices of reading and writing are changing in response to new communications technology. As Richard A. Lanham (1993) pointed out, because electronic text is composed of not only alphabetic text but also a multitude of visual images, students must be taught skills for reading and composing online that differ from skills traditionally taught in writing classes. For instance, electronic text is far more self-conscious of the fact that when we read, we typically treat print text as a transparent window on reality; we look through the text rather than at it. Electronic text requires that we do both-and it requires us to oscillate between visual, auditory, and textual perception. One of the most popular hypermedia dissertations published in the NDLTD, an architectural student's research into the space of Middle Eastern Turkish coffee shops, exemplifies how these dual 
concepts of immediacy (looking through) and hypermediacy (looking at) can play out through the use of video. What could be a more immediate experience of the environment of a Turkish coffee shop than an embedded digital video/audio clip of the space? Only a visit to the coffee shop itself. Though clearly mediated by the technology required to produce it, the video brings us closer to the sensory experience of the environment. Yet this very sense of immediacy is actually produced by the hypermediacy of the clip, which makes no pretense of concealing itself. We look at it and through it all at once. Multimedia versions of published research can be simultaneously more hypermedic and more immediate than print text.

As linguist Gunther Kress (1999) notes, there is an ever-growing reliance in multimedia authoring on the rhetoric of the visual and the marginalization of text -a move toward text as a pointer to rather than an explanation of visual information. As scholars who have traditionally written and published almost exclusively in text, we do not yet, perhaps, perceive the need to take such developments into account in preparing graduate students for the profession. But as our practices of writing continue to undergo transformation through digital media, future scholars in all disciplines will require more specific training in the use of tools that allow them to effectively present their research.

\section{Conclusion}

Academic scholarship is currently undergoing the process Jay David Bolter and Richard Grusin term remediation-the process by which one medium is reformed and improved upon by another. ETDs can help speed this process in academe, where innovation is many times (and quite ironically) slow to diffuse. As Bolter and Grusin (1999) noted, at the beginning of the twenty-first century we

.... are in an unusual position to appreciate remediation, because of the rapid development of new digital media and the nearly as rapid response by traditional media. Older electronic and print media are seeking to reaffirm their status within our culture as digital media challenge that status. (p. 5)

Outside academe, the professions of medicine and law, business, government and even the arts are undergoing an electronic revolution. Physicians and lawyers now rely on electronic databases. Interactive video is used for medical training and diagnosis, and CD-ROM has been recommended to replace periodicals in law libraries. Yet, in academe, we continue to train future scholars to write books; we persist in requiring the authorship of a linear, hierarchically structured print dissertation, grounded in conceptions of Romantic authorship that has historically been underused by the world-wide scholarly community. It is time to move on.

In a time when developing countries' need for new knowledge has never been greater, when graduate students' need for richer, more effective means of presenting research are becoming more and more apparent, and when digital technology provides the capability to meet those needs, graduate schools, faculty, and administration must develop and support initiatives to institute the electronic publication of theses and dissertations. Graduate school efforts to research ETDs and to update policies to include important guidelines and standards for electronic publication of student research must be stepped up. The world needs broader 
access to the knowledge of its scholars, and graduate students need access to the training and tools that will allow them to present that knowledge effectively in a digital world.

\section{Note}

1. Remediation, defined by Jay David Bolter and Richard Grusin (1999), is the process by which one medium is improved upon or reformed by another. Because older media achieve a sense of immediacy or transparency over time, their remediation by new media has the potential to call attention once again to their status as media.

Jude Edminster teaches technical writing and coordinates the Writing Center at the University of South Florida. Edminster has been engaged in ethnographic investigation of ETD implementation. She can be reached at <jedmins1@tampabay.rr.com>.

Joe Moxley is a professor of English and directs the Digital Media Institute at the University of South Florida, a project involving faculty and graduate students interested in New Media scholarship. A member of the NDLTD Steering Committee, Moxley directed the Third International Symposium on ETDs. He can be reached at < moxley@dmi.usf.edu>.

\section{References}

Bauman. Marry. (1999). The evolution of Internet genres. Computers and Composition, f6, 269-281.

Bolter. Jay David. (1991). Writing space: The computer, hypertext and the history of writing. Hillsdale, NJ: Lawrence Erlbaum Associates.

Bolter. Jay David. \& Grusin, Richard. (1999). Remediation: Understanding new media. Cambridge, MA: MIT Press.

Copyright Act of 197617 U.S. C107 (1994).

Electronic theses and dissertations: 200f survey of editors and publishers. [Online] Retrieved July 20, 2001 from $\langle$ http://lumiere lib.vt.edu/surveys 〉.

Electronic transmission of theses and dissertations at UNT A report from the ad hoc committee. (1997). Denton TX University of North Texas. Toulouse School of Graduate Studies [Online] Retrieved December 15, 2001 from 〈http://www.unt.edu/etd/ETDs.htm>.

Exon, Maggie. (1995). Long-term management issues in the Preservation of electronic information. Paper presented at the 2nd National Preservation Office Conference: Multimedia Preservation-Capturing the

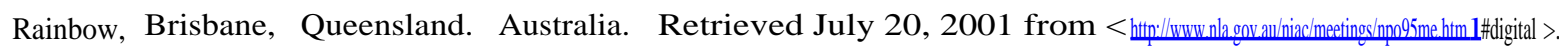

Holtzman. Steven. (1997). Digital mosaics: The aesthetics of cyberspace. New York: Simon \& Schuster.

J aszi, Peter. ( 1991). Toward a theory of copyright: The metamorphoses of "authorship." Duke Law Journal, 455-502. Kress, Gunther. (1997). Before writing: Rethinking the paths to literacv. New York: Routledge.

Kress, Gunther. (1999). English at the crossroads: Rethinking curricula of communication in the context of the turn to the visual. In Gail E. Hawisher \& Cynthia L. Selfe (Eds.), Passions, pedagogics. and 2I st century technologies (pp. 66-88). Logan. UT: Utah State University Press. 
Lanham, Richard A. (1993). The electronic word: Democracy, technology and the arts. Chicago: University of Chicago Press.

Lenzo, Kate. (1995). Validity and sell' reflexivity meet postructuralism: Scientific ethos and the transgressive self. Educational Researcher. 24, 17-23.

Malone, Thomas L. (1981). A history of the (lot tot of philosophy dissertation in the United States 1561-1930. Unpublished doctoral dissertation, Wayne State University, Detroit, MI.

McClelland. Charles E. (1980). State, society, and university in Germany 1700-1914. Cambridge: Cambridge University Press.

NDLTD Member Survey. Retrieved July 20, 2001 from < http://lumiere lib.vt.edu/surveys >.

NDLTD Steering Committee Meeting Minutes, September 15, 2000. Retrieved December 15, 2001 from 〈http://scholar.lib.vt.edu/theses/NDLTD/SC20000915.1)(11 〉.

Parry, Sharon. (1998). Disciplinary discourse in doctoral theses. Higher Education, 36, 273-299.

Richardson. Laurel. (1994). Writing: A method of inquiry. In Norman K. Denzin \& Yvonna S. Lincoln (Eds.), Handbook of qualitative research. Newbury Park, CA: Sage.

Scheftic. C. (1997). Intellectual property rights \& wrongs. Retrieved November 17, 2001 from 〈http://www.geom.umn.edw/scheftic/Talks/lPRW/intent.html >.

Sony Corporation of America v. Universal City Studios Inc., 464 U.S.429 (1984).

Spi ${ }^{\mathrm{g}}$ elman, Candac. (2000). Across Property lines. Carbondale: Southern Illinois University Press.

Thomas, R. Murray \& Brubaker. Dale L. (2000). Theses and dissertations: A guide to planning, research, and writing. Westport, CT: Bergin \& Garvey.

Thwing, Charles F. (1928). The American and the German university: One hundred years of history. New York: The Macmillan Company.

2000/2001 ETD Author Survev. Retrieved December 15, 2001 from < http://lumiere.lib.vt.edu/surveys >.

U.T. Office of Graduate Studies Electronic Dissertations. Retrieved July 20, 2001 from < htp //www utextts.edu/ogs/etd/project/summary html >.

Woodmansee, Martha, \& Jaszi, Peter. (1994). The construction of authorship: Textual appropriation in law and literature. Durham, NC: Duke University Press.

Woodmansee Martha, \& Jaszi, Peter. (1995). The law of texts: Copyright in the academy. College English, 57, 769-787. 